\title{
Study of the Mucoadhesive Potential of Carbopol Polymer in the Preparation of Microbeads Containing the Antidiabetic Drug Glipizide
}

\author{
Khokan Bera, ${ }^{1,3,4}$ Bhaskar Mazumder, ${ }^{2}$ and Jasmina Khanam ${ }^{3}$
}

Received 6 May 2015; accepted 12 August 2015; published online 4 September 2015

\begin{abstract}
The present investigation was aimed at exploitation of the mucoadhesive potential of carbopol 934P polymer in developing microbeads of glipizide (GLP) for its effectivity in controlling blood sugar in diabetic patients. Various batches of GLP beads were prepared by an emulsion-solvent evaporation technique using the release-retarding polymer carbopol and subjected to a systematic evaluation such as physical characterization, ex vivo mucoadhesion, hydration and erosion test, and in vitro drug release; and instrumental and in vivo studies were performed with the best formulation. The highest yield and loading efficiency were observed as 94 and $\sim 90 \%$, respectively. The mean particle size of the microbeads ranged from 832 to $742 \mu \mathrm{m}$. The oval shape of the microbeads with slight roughness was apparent in the SEM micrograph. The release period was extended till $18 \mathrm{~h}$. In vitro release of the drug from the beads followed the diffusion and erosion mechanism. In the oral glucose tolerance test (OGTT), there is a significant $(p<0.01)$ reduction in fasting blood glucose levels in Wistar rat and guinea pig in comparison with that using the marketed product. Results indicated that process parameters-drug-polymer ratio, concentration of the surfactant, and stirring speed-controlled the various characteristics of the microparticles. The mucoadhesivity test ensured strong adherence of the beads to the mucosal membrane in $\mathrm{pH} 1.2$ for a prolonged period. Owing to the mucoadhesivity of carbopol 934P, prolonged release of GLP and reduction of fasting sugar in the animal model were observed to a satisfactory level, and thus, management of diabetes in a better manner is expected with this new formulation.
\end{abstract}

KEY WORDS: carbopol 934P; ex vivo absorption; ex vivo mucoadhesion; glipizide; hydration.

\section{INTRODUCTION}

The multiparticulate dosage form is a unique device intended to enhance the release period of a drug in the body, but the lacunae had been recognized in many cases by formulation scientists as the transit period of the particles in the gastrointestinal tract (GIT) is short owing to less adherence ability of the microparticles to the GIT membrane for a prolonged period; as a result, particles exit the site of absorption before the complete release of the drug. The problem of this shorter residence time at the specific site can be overcome by designing gastroretentive dosage forms (GRDFs) which are retained in the stomach for an extended period, thereby leading to an enhanced bioavailability of the drugs. GRDFs are developed either by imposing floatability or adhesivity to the solid dosage forms for oral administration. With the advent of varieties of polymers, the concept of mucoadhesion $(1,2)$ emerged as a

\footnotetext{
$\overline{{ }^{1} \text { Calcutta Institute of Pharmaceutical Technology \& AHS, Uluberia, }}$ Kolkata, 711316, West Bengal, India.

${ }^{2}$ Department of Pharmaceutical Sciences, Dibrugarh University, Dibrugarh, Assam, India.

${ }^{3}$ Department of Pharmaceutical Technology, Jadavpur University, Kolkata, West Bengal, India.

${ }^{4}$ To whom correspondence should be addressed. (e-mail: kbjadavpur123@gmail.com)
}

potential application in the drug delivery system which is intended to enhance bioavailability and residence time of the drug in the GIT and to provide better contact between the drug and the adsorbing surface. "Gastroretentive formulation" must be able to withstand the strong intense contractions of the stomach for a considerable period of time. Designing of a mucoadhesive drug delivery system should be based on prior understanding of the structure, functioning, and composition of the mucus, physiological $\mathrm{pH}$, and mechanisms involved in bioadhesion and diseased condition.

The mucus layer is secreted by goblet cells, and it is composed of glycoproteins, lipids, electrolytes, and water and removed periodically from the epithelial layer by peristaltic forces. Turnover time varies from 4 to $6 \mathrm{~h}$. The thickness of the viscous mucus layer and the turnover time of the mucus play an important role in vivo on the release of the drug at a particular site of the GIT (3).

Recently, many investigators have used a combination of polymers using carbopol with other polymers for the development of a mucoadhesive controlled release delivery system of various drugs (4-11). Earlier, Patel and Charva (12) and Patel et al. (13) observed the effect of combined polymers involving carbopol 934P in an attempt to formulate a mucoadhesive drug delivery system for its application to various mucosal sites, but there have been few reports on the use of a single polymer (carbopol 934P) in developing mucoadhesive multiparticulates. We have reported an ex vivo mucoadhesive 
study and investigated the satisfactory percentage of drug entrapment efficiency (\% DEE). On the other hand, few investigators have performed ex vivo absorption studies using a goat intestine segment for assessing the intestinal permeability of a drug. Above all, in vivo hypoglycemic activity is observed in Wistar rat and guinea pig also.

In the controlled release field, a biodegradable and biocompatible mucoadhesive material such as carbopol (CP934P, carboxypolymethylene) is found to be very much effective owing to its swellability and biosafety. It is not absorbed by body tissues, and moreover, it is less costly. Its carboxylate moiety on the polymer backbone ionizes at higher $\mathrm{pH}$ $\left(\mathrm{p} K_{\mathrm{a}} \sim 6.0\right)$, resulting in repulsion between the negatively charged carboxylate ions, which add to the swelling of the polymer. Carbomers show larger dissolution times at lower concentrations than those of other excipients because of its high viscosity (35,000-39,400 $\mathrm{mPa}$ s).

In the recent past, the rheological (14-19) and mucoadhesive properties $(4-6,20,21)$ of different kinds of carbopol gels in water had been studied to exercise the potentiality of CP934P as a mucoadhesive agent. So far, there had been few reports that evaluated the ex vivo mucoadhesion performance $(7,8,22,23)$ of hypoglycemic agents. Sandri et al. (24) had highlighted the use of polyacrylic acid in the bilayered formulation for the metformin hydrochloride formulation.

Dosage forms if retained on the mucosal layer would increase the absorption, improve drug efficiency, and decrease dose requirements. In this context, a strong need was felt to develop a dosage form that would deliver the antidiabetic drug glipizide into the stomach for a longer period owing to the bioadhesion mechanism, and it would increase the efficiency of the drug providing a sustained action. Thus, an attempt was made in the present investigation to use CP934P as a single carrier polymer, in order to prepare mucoadhesive multiparticulates of glipizide (GLP) $\left(t_{1 / 2} \sim 3.4 \pm 0.7 \mathrm{~h}\right)$.

It is a second-generation sulfonylurea and is prescribed typically to treat type II diabetes (25). Its absorption is favored at $\mathrm{pH}$ lower than its $\mathrm{p} K_{\mathrm{a}}(\sim 5.9)$. The effects of variability of $\mathrm{pH}$ of the GIT on the characteristics of the drug and polymer determine the extent of the release and absorption of the drug through the gastric membrane. The prepared microparticles were subjected to in vitro, ex vivo, and in vivo tests in order to assess the potentiality of $\mathrm{CP}$ as a mucoadhesive agent in developing a sustained release dosage form of GLP.

\section{MATERIALS AND METHODS}

\section{Materials}

GLP (pure drug) was kindly provided by Arandy Lab Ltd, Hyderabad. CP934P was purchased from Loba Chemie Pvt. Limited, Mumbai. Acetone, $n$-hexane, and Span 80 were obtained from Merck Specialties Pvt. Ltd., Mumbai, India. Other chemicals used were of analytical grade.

\section{Assay of Glipizide}

The aqueous solution of GLP at different dilutions (5 to $50 \mathrm{mg} / \mathrm{ml}$ ) was prepared $(n=4)$ with phosphate buffer solution (PBS, pH 7.4), and the absorbance of the solution was measured by a UV/VIS spectrophotometer (U-2001 Hitachi, Japan) at $\lambda_{\max }$ of $276 \mathrm{~nm}$. The method was validated for linearity, mean error/accuracy $(0.65 \%)$, and precision $(1.57 \%)$.

\section{Preparation of GLP-CP934P Microbeads}

\section{By Solvent Evaporation Technique}

Glipizide-embedded microbeads were prepared by the "solvent evaporation technique" (9) using CP934P as a release-retarding polymer. A specified amount of polymer was solubilized in a fixed amount of acetone $(8.5 \mathrm{ml})$. The drug was dispersed thoroughly in a polymer solution. The resulting mixture was added to a continuous phase (light liquid paraffin, $90 \mathrm{ml})$ which contains Span $80(1 \% \mathrm{w} / \mathrm{v})$ as an emulsifier. The dispersion was agitated continuously at $510 \mathrm{rpm}$ in a $250-\mathrm{ml}$ beaker by a mechanical stirrer. The liquid was stirred till $45 \mathrm{~min}$ until the acetone was evaporated completely. After emulsification, the settled particles were separated out by filtration. The batch of solidified microparticles was washed five times with a $50-\mathrm{ml}$ portion of $n$-hexane and, subsequently, dried at room temperature $\left(28^{\circ} \mathrm{C}\right)$ for $24 \mathrm{~h}$.

\section{Characterization of the Microbeads}

The yield of the product batch of multiparticulates was calculated as follows:

$$
\begin{aligned}
\text { Yield }(\%)= & \frac{\text { Practical mass of product batch }}{\text { Initial load (mass of drug }+ \text { mass of polymer) }} \\
& \times 100
\end{aligned}
$$

The entrapped amount of the drug within microparticles was extracted in PBS ( $\mathrm{pH}$ 7.4) following the method of Patel et al. (26), and the drug content was estimated by the UV/VIS spectrophotometer. The following expression was used to calculate DEE:

$$
\operatorname{DEE}(\%)=\frac{\text { Drug content as per assay }}{\text { Drug content as per initial load }} \times 100
$$

\section{Determination of the Hydration Index and Study of Erosion}

The CP polymer gets hydrated in an aqueous medium and forms a gel. So, the product particles formed with $\mathrm{CP}$ were subjected to assess gravimetrically its ability of being hydrated and eroded in the aqueous medium of $\mathrm{pH} 1.2 / 7.4$, as these phenomena govern the diffusion of the drug from controlled release polymeric particles. Hydration and erosion studies were performed at $37 \pm 1^{\circ} \mathrm{C}$ and $50 \mathrm{rpm}$ in an aqueous medium $(900 \mathrm{ml})$ of $\mathrm{pH} 1.2 / 7.4 \mathrm{using}$ a batch of $50 \mathrm{mg}$ of GLP microbeads (27) in each experimental set. Microbeads got hydrated up to $8 \mathrm{~h}$ approximately and it remained mostly unchanged till $\sim 9.5 \mathrm{~h}$. After complete hydration of the microbeads, erosion of the CP polymer from the beads began and continued till $16 \mathrm{~h}$ approximately. At specific time intervals, microbeads were removed from the medium, patted 
gently with tissue paper, weighed, and dried at $60^{\circ} \mathrm{C}$ until constant weight was determined. Percent weight gain (hydration) and percent mass loss (erosion) were calculated as follows:

$$
\begin{gathered}
\% \text { weight gain }=\frac{W_{\mathrm{f}}-W_{\mathrm{i}}}{W_{\mathrm{i}}} \times 100, \text { and } \% \text { mass loss } \\
=\frac{\text { original weight }- \text { remaining }(\text { dry }) \text { weight }}{\text { original weight }} \times 100
\end{gathered}
$$

Here, $W_{\mathrm{i}}$ and $W_{\mathrm{f}}$ are the initial and final weights of the microbeads, respectively.

\section{Ex Vivo Mucoadhesive Strength Determination}

Ex vivo mucoadhesive studies were performed on normal healthy Wistar rats weighing 262-305 g each. Approval from the Institutional Animal Ethical Committee (IAEC) was obtained before the start of the experiments. Six groups of healthy Wistar rats $(n=3)$ were fasted (with water) overnight and then 20 microbeads $\left(N_{\mathrm{i}}\right)$ were ingested (28) through an oral feeding tube. These six groups were then sacrificed at an interval of $0,2,4,6,8$, and $10 \mathrm{~h}$, and their stomach and intestine parts were separated. The stomach and intestine parts were then incised longitudinally to observe the number of microbeads still adhering to these regions $\left(N_{\mathrm{f}}\right)$. The ex vivo adhesive strength was calculated as follows:

$\%$ of Mucoadhesion $=\frac{N_{\mathrm{i}}-N_{\mathrm{f}}}{N_{\mathrm{i}}} \times 100$

where $N_{\mathrm{i}}$ and $N_{\mathrm{f}}$ were the initial number of beads applied and the number of beads that adhered to the tissue up to $10 \mathrm{~h}$.

\section{Micromeritic Properties of GLP-Loaded CP934P Microbeads}

The particles were characterized for their micromeritic properties such as particle size, shape, bulk density (BD), tapped density (TD), Carr index (CI), Hausner's ratio, and angle of repose. The average particle size of the batch of GLPCP934P particles was determined with a Leica-YM-750 (Wetzlar, Germany), phase contrast dark field laser light scattering instrument. Isobutanol was used as the insoluble dispersion medium. The standard procedures were adopted to determine BD, TD, CI, Hausner's ratio, and angle of repose (29-31). Each data is the mean of three observations with standard deviation.

\section{In Vitro Study of Drug Release (\%) and Determination of Release Kinetics}

The dissolution study of the drug in vitro was performed in a USP dissolution apparatus (rotating basket, Electolab, India) as per USP XXVI, 2003 (32). A dissolution medium of $900 \mathrm{ml}$ was used which had been maintained at $\mathrm{pH} 1.2$ for the first $2 \mathrm{~h}$ and PBS ( $\mathrm{pH}$ 7.4) for the rest of the period of the study till $18 \mathrm{~h}$ at $37 \pm 0.5^{\circ} \mathrm{C}$, and the stirring rate was maintained at $50 \mathrm{rpm}$. In each study, a drug-loaded formulation containing $20 \mathrm{mg}$ equivalent amount of GLP was used. Samples were withdrawn at intervals. Each sample $(5 \mathrm{ml})$ was withdrawn carefully from the dissolution medium at various time intervals and was replaced by an equal volume $(5 \mathrm{ml})$ of fresh medium. A sink condition was maintained during the dissolution study (aqueous solubility of pure GLP at $\mathrm{pH} 7.4$ and $\mathrm{pH}$ 1.2 is $7.21 \mathrm{mg} / 100 \mathrm{ml}$ and $3.66 \mathrm{mg} / 100 \mathrm{ml}$ at $25^{\circ} \mathrm{C}$, respectively). Collected samples were filtered and analyzed by a spectrophotometer (Hitachi, model U-2001) at $\lambda_{\max }$ of $276 \mathrm{~nm}$. The results measured in triplicate are expressed as a percentage of the drug release.

To identify the release mechanism, it is the usual practice to fit the percent release data in various established equations. The drug release data were fitted to kinetic model equations which include the zero-order equation, $M=k_{0} t$; the first-order equation, $\log (\mathrm{UM})=k_{1} t / 2.303$; the Higuchi model equation, $M=k_{\mathrm{h}} \sqrt{ } t$; and the Korsmeyer-Peppas model, $M=k_{\mathrm{pt}} t^{n} . M$ is the cumulative percentage of drug released at time $t$ with respect to the percentage release of the drug at an infinite time. UM denotes the fraction of the drug unreleased at time $t$. In the present work, it was assumed that the whole quantity of the drug was released at an infinite time. $k_{0}, k_{1}$, and $k_{\mathrm{h}}$ are the rate constants of zero-order, first-order, and Higuchi model, respectively; and $k_{\mathrm{kp}}$ and $n$ are the rate constant and exponent in the Korsmeyer-Peppas model, respectively.

The dissolution profiles were compared by calculating the similarity factor, $f_{2}$, as proposed by Moore and Flanner. The equation of similarity factor is represented as follows:

$f_{2}=50 \log \left[1+\frac{1}{n} \sum_{n-1}^{n}\left(R_{\mathrm{t}}-T_{\mathrm{t}}\right)^{2}\right]^{-0.5} \times 100$

Here, $R_{\mathrm{t}}=$ average percentage drug dissolved from the reference formulation and $T_{\mathrm{t}}=$ average percentage drug dissolved from the test formulation.

\section{Stability Test}

The best formulation (CG5) of GLP-CP934P microparticles was tested for stability studies. Three samples of CG5 were stored at $4 \pm 1^{\circ} \mathrm{C}$ and $25 \pm 2^{\circ} \mathrm{C}$ at $60 \pm 5 \% \mathrm{RH}$ and at 37 $\pm 2{ }^{\circ} \mathrm{C}$ at $65 \pm 5 \% \mathrm{RH}$. After 90 days, the drug release of the selected formulation was determined by the method discussed previously.

\section{Solid-State Studies by Instrumental Analysis}

Fourier transform infrared (FTIR) spectroscopy of the samples (pure GLP, CP934P, and CG5) was performed using IR Prestige-21, Shimadzu, Japan. A sample of $2 \mathrm{mg}$ was ground thoroughly with $\mathrm{KBr}$ and the pellets were formed under a hydraulic pressure. The study was performed over a spectral range of $4000-400 \mathrm{~cm}^{-1}$.

X-ray diffraction (XRD) study was done by using a Rigaku Miniflex diffractometer (Rigaku Co., Ltd., Japan) using a $\mathrm{Kb}$ filter and $\mathrm{Cu}$ radiation, at a voltage of $30 \mathrm{kV}$ and a current of $15 \mathrm{~mA}$ at $25^{\circ} \mathrm{C}$. The samples $(5 \mathrm{mg})$ were mounted onto the diffractometer and the diffraction patterns were recorded over $5-60^{\circ}$ at $2 \theta$ at a scan rate of $1^{\circ} \mathrm{min}^{-1}$.

Differential scanning calorimetry (DSC) study of selected samples was carried out using a Perkin-Elmer Pyris Diamond 
(Singapore) TG/DTA analyzer. The DSC studies on the samples $(5 \mathrm{mg})$ were performed by heating samples at a heating rate of $8^{\circ} \mathrm{C} / \mathrm{min}$ over a temperature range of $30-350^{\circ} \mathrm{C}$ in closed aluminum pans under nitrogen atmosphere $(150 \mathrm{ml} /$ $\min )$.

\section{Surface Topography and Surface Characterization by Scanning Electron Microscopy}

The morphology of the particles was examined by scanning electron microscopy (SEM) using a Jeol-make (UK) electron microscope. A sample of microbeads was fixed on a brass stub and coated with a gold palladium layer under argon atmosphere by using a gold sputter module in a high-vacuum evaporator. The instrument was set at an excitation voltage of $17 \mathrm{kV}$.

\section{Acute Toxicity Test}

Acute oral toxicity of the formulation was carried out in Wistar rat according to the guidelines set by Organization for Economic Co-operation and Development (OECD-425). The starting dose was selected to be $2000 \mathrm{mg} / \mathrm{kg}$ body weight of the animal, and finally, a dose of $5000 \mathrm{mg} / \mathrm{kg}$ body weight was evaluated for toxicity. The Wistar rats $(n=6$, average weight $\sim 275 \mathrm{~g}$ ) were under observation to check their behavior for the first $2 \mathrm{~h}$ of administration and mortality if any within $48 \mathrm{~h}$.

\section{Ex Vivo Absorption Study in a Goat Intestine Segment}

This study was performed following the method of Karasov and Diamond (33). A segment of a small intestine of a male goat was bought from a local market. An intestinal segment (10 cm length, $0.80 \mathrm{~cm}$ inner diameter of the lumen) was cut and carefully cleared of mucus by rinsing thoroughly with warm Krebs-Ringer phosphate buffer (KRPB) solution (34). After tying up one end of this segment, the inner cavity of the sac/lumen was filled with a dissolution medium (PBS, $\mathrm{pH}$ 7.4) and a sample of microparticles containing $5 \mathrm{mg}$ of an equivalent amount of GLP. The other end was ligated using silk braided sutures. The sac was then fitted between the two ends of a "disintegration tester" and immersed in $1000 \mathrm{ml}$ of the solution (PBS, $\mathrm{pH} 7.4,37 \pm 0.5^{\circ} \mathrm{C}, 25 \mathrm{rpm}$ ) kept in the basket. The drug was permeated through the mucosal layer (absorption compartment) to the outside medium (serosal compartment). Samples were withdrawn from the serosal compartment at preselected intervals up to $24 \mathrm{~h}$ with replacement by a fresh medium and were analyzed by the UV spectrophotometer at $276 \mathrm{~nm}$. At the appropriate time intervals, the sac was removed from the medium and the liquid that remained in the intestinal sac was collected from one end of the sac. The inner surface was exposed by vertical incision, and the microparticles were collected from the surface of the mucosal layer and dried at $37^{\circ} \mathrm{C}$. The mucus of the intestinal segment was scraped off with a microscopic slide, and the mucosal scrapings were homogenized in $0.9 \%$ saline and analyzed. Thus, the drug that remained in the liquid of the intestinal sac, the microbeads, and the mucosal layer were determined at the end of $24 \mathrm{~h}$ to check the mass balance of GLP. The permeability of the drug was calculated as the amount of GLP permeated per unit area per hour.
The mass balance of GLP was shown for some selective formulations (CG5, CG6, CG9, CG10, CG12, and CG15), to check for any degradation of the drug during the study. A plot was constructed to correlate in vitro dissolution/drug release and ex vivo absorption/permeation of GLP at common time intervals (CG5).

\section{In Vivo Hypoglycemic Activity of GLP Microbeads in Wistar Rat and Guinea Pig}

In vivo evaluation studies for GLP-CP934P microparticles were performed on healthy normal Wistar rats, weighing 262-305 g each by measuring the hypoglycemic effect produced after oral administration of GLP (32). The approval from the IAEC was obtained before starting the animal experiments which was conducted in compliance with the standard integral guidelines.

Three groups (A, B, and C) of healthy Wistar rats $(n=6)$ were kept on fast (with water) at least $12 \mathrm{~h}$ before starting the in vivo studies. A dose of $800 \mu \mathrm{g}$ of pure drug per kilogram of body weight was administered orally to the animals of group A. Animals of group B and group C were orally administered with an equivalent dose of marketed SR tablets (Glynase 5 SR, USV Ltd., Mumbai, India) and mucoadhesive GLP microbeads (CG5), respectively. The dosage of the drug administered was calculated on the basis of the drug content (i.e., Glynase $5 \mathrm{SR}-5.95 \mu \mathrm{g} / \mathrm{mg}$ and CG5 $-268 \mu \mathrm{g} / \mathrm{mg}$ ). Blood sample $(1 \mathrm{ml})$ was collected from each rat from the eyeball through the angle of the ocular cavity using small capillary tubes at time intervals up to $24 \mathrm{~h}$, and blood glucose level was estimated by using glucose oxidase-peroxidase reactive strips (Accu-Chek, Roche Diagnostics, USA). The same evaluation study was carried out on healthy normal guinea pigs weighing 840-910 g each to explore the hypoglycemic effect in accordance with standard integral protocol. Blood glucose levels were determined and the percentage reduction in glucose levels with respect to the initial glucose level was calculated. Each value was expressed as mean \pm SD. Statistical difference was analyzed by Student's $t$ test. For a value of $p<0.05$, the difference was considered significant.

\section{RESULTS AND DISCUSSION}

CP934P is well known as a mucoadhesive polymer which is selected appropriately as a release retardant matrix polymer in order to develop a controlled release drug delivery system (microparticles) of the antidiabetic drug GLP. GLP is absorbed better from the acidic $\mathrm{pH}$ of the stomach than from the basic $\mathrm{pH}$ environment of the intestine as the drug is largely present in unionized form owing to its $\mathrm{p} K_{\mathrm{a}}$ value as 5.9. As its biological half-life is short $(3.4 \pm 0.7 \mathrm{~h})$, so the problem of frequent administration can be overcome by prolonging its residence period in the stomach, and this was achieved by entrapping the drug in a matrix of a mucoadhesive polymer, CP. It is the usual practice to use an additional secondary polymer when a primary polymer fails to provide the desired extended period of release and mucoadhesivity. Earlier, Patel et al. $(12,13)$ observed the effect of combined polymers involving CP934P to formulate a mucoadhesive drug delivery system. In the present investigation, the formulation is an improved one, prepared with a single polymer (CP934P) 
which could achieve a greater sustained effect $(18 \mathrm{~h})$ with appreciable mucoadhesivity and higher drug entrapment efficiency $(\sim 90 \%)$ than that reported earlier. We have reported ex vivo mucoadhesive study and ex vivo absorption study. These noninvasive techniques are an indirect approach to indicate the extended release of the drug and to assess the permeability of the drug through the membrane before carrying out any animal studies. The study was comprehensive in a way that it was followed by an in vivo experiment to assess the hypoglycemic activity in Wistar rat and guinea pig also.

The solvent evaporation technique makes the preparation of microparticles very simple and rapid, as acetone evaporates fast and it provides a dehydrating effect. Liu et al. (9) prepared the carbopol microspheres using Span 80 (HLB 4.3) to form mucoadhesive microspheres of controlled release dosage form. The HLB value of the surfactant and its concentration are important parameters that control the average size of emulsion globules and subsequent percentage yield of the microspheres. The fraction of dispersed phase consisting of drug-polymer-solvent is also an important factor which controls the viscosity of the dispersion as reported by Lee et al. (35). All the controlling parameters were selected and screened logically and by trial. Various batches of microparticles were prepared as per the set of combinations of formulation variables as mentioned in Table I with batch codes. Chosen variables were drug-polymer ratio; concentration of the surface active agent, Span 80; and stirring speed of the impeller.

\section{Characterization of Microparticles}

In the multiparticulate system, total surface area matters a lot concerning drug release and its subsequent absorption in the system. The rate of diffusion of the drug through the polymer matrix into continuous phase via interface is physically dependent on the tortuous path and total surface area which in turn depends on the average particle size of microparticles. Therefore, it is necessary to determine the average particle size of the batches and to study the effects of other factors on which the average size $\left(d_{\mathrm{p}}\right)$ of particles depends. The prepared microparticles were oval shaped, free flowing, and discrete with relatively smooth surfaces. The rotational speed of the impeller (510 rpm) and the period of stirring (45 min) were fixed by trial. We observed an increase of average particle size as the drug-polymer concentration increases that might be due to the high viscous nature of the polymer solution which created larger droplets in the emulsion. Average particle size was obtained in the range of 742.01 \pm 9.20 to $832.30 \pm 8.41 \mu \mathrm{m}$ for various batches of particles, and it was controlled mainly by the drug-polymer concentration $\left(X_{1}\right)$, concentration of Span $80\left(X_{2}\right)$, and stirring speed $\left(X_{3}\right)$. It was revealed that bulk density, true density, compressibility index, angle of repose, and Hausner's ratio of formulations CG1-CG15 ranged from $0.577 \pm 0.022$ to $0.723 \pm 0.021 \mathrm{~g} / \mathrm{ml}$, $0.680 \pm 0.009$ to $0.826 \pm 0.012 \mathrm{~g} / \mathrm{ml}, 12.46 \pm 0.91$ to $15.65 \pm 1.10$, $25.33 \pm 0.97$ to $28.33 \pm 1.16^{\circ}$, and $1.14 \pm 0.041$ to $1.19 \pm 0.088$, respectively. The results of the above data indicate that the particles are free flowing in nature. Uniform flowability is a basic requirement in the preparation of tablets and filling of capsules.

The hydration ability of $\mathrm{CP}$ enhances its adhesivity and facilitates long residence and prolonged release of the drug. Water molecules bind to the polymer carboxyl groups which are required for adhesion and swelling (36), and polymer chains are eroded in the long run. However, excessive swelling rate causes reduced mucoadhesion leading to fast erosion. Water uptake capacity (hydration index (HI), weight gain) of CP934P is displayed in Table II showing HI of $1.92-3.61 \%$ at $\mathrm{pH} 1.2$ which is slightly higher than that at $\mathrm{pH}$ 7.4. Weight loss (erosion study (ES) \%) was similarly observed to be higher at $\mathrm{pH}$ 1.2. Formulation CG5 showed the highest HI $(3.61 \pm 0.12$, pH 1.2 and 2.55 $\pm 0.11, \mathrm{pH} 7.4$ ).

Table I. Effect of Formulation Variables on the Measured Responses

\begin{tabular}{|c|c|c|c|c|c|c|c|}
\hline \multicolumn{8}{|c|}{ Controlling variables } \\
\hline $\begin{array}{l}\text { Batch } \\
\text { code }\end{array}$ & $\begin{array}{l}\text { Drug-polymer } \\
\quad \text { ratio, } X_{1}(w / w)\end{array}$ & $\begin{array}{l}\text { Surfactant } \\
\text { concentration, } \\
X_{2}(w / v)\end{array}$ & $\begin{array}{l}\text { Stirring speed, } \\
X_{3}(\mathrm{rpm})\end{array}$ & $\begin{array}{l}\% \text { drug } \\
\text { release }\end{array}$ & $\%$ DEE & $\%$ yield & $\begin{array}{l}\text { Mean particle } \\
\quad \text { size, } d_{\mathrm{p}}(\mu \mathrm{m})\end{array}$ \\
\hline CG1 & $1: 1.75$ & 0.80 & 480 & $61.23 \pm 1.09$ & $58.50 \pm 1.19$ & $63.69 \pm 0.76$ & $826.29 \pm 6.36$ \\
\hline CG2 & $1: 1.75$ & 0.80 & 540 & $87.74 \pm 1.15$ & $81.89 \pm 0.67$ & $84.54 \pm 0.91$ & $792.19 \pm 4.67$ \\
\hline CG3 & $1: 1.75$ & 1.00 & 510 & $74.08 \pm 0.45$ & $70.34 \pm 1.94$ & $76.42 \pm 1.34$ & $786.80 \pm 7.80$ \\
\hline CG4 & $1: 1.75$ & 1.20 & 480 & $71.06 \pm 1.23$ & $68 . .90 \pm 0.30$ & $64.69 \pm 1.87$ & $774.98 \pm 5.26$ \\
\hline CG5 & $1: 1.75$ & 1.20 & 540 & $96.83 \pm 1.56$ & $89.45 \pm 1.19$ & $95.11 \pm 0.92$ & $714.56 \pm 9.70$ \\
\hline CG6 & $1: 2.60$ & 0.80 & 510 & $65.07 \pm 1.01$ & $64.23 \pm 0.87$ & $68.87 \pm 1.23$ & $813.20 \pm 5.66$ \\
\hline CG7 & $1: 2.60$ & 1.00 & 480 & $58.65 \pm 0.57$ & $57.88 \pm 0.99$ & $61.76 \pm 0.93$ & $823.09 \pm 9.12$ \\
\hline CG8 & $1: 2.60$ & 1.00 & 510 & $68.77 \pm 1.01$ & $65.10 \pm 2.03$ & $70.98 \pm 1.34$ & $799.36 \pm 4.40$ \\
\hline CG9 & $1: 2.60$ & 1.00 & 540 & $92.77 \pm 0.88$ & $84.16 \pm 1.32$ & $91.50 \pm 1.50$ & $812.27 \pm 8.06$ \\
\hline CG10 & $1: 2.60$ & 1.20 & 480 & $68.45 \pm 1.03$ & $70.48 \pm 1.05$ & $76.13 \pm 0.52$ & $786.05 \pm 5.40$ \\
\hline CG11 & $1: 3.45$ & 0.80 & 480 & $58.23 \pm 1.25$ & $56.67 \pm 0.86$ & $59.08 \pm 0.49$ & $742.01 \pm 9.20$ \\
\hline CG12 & $1: 3.45$ & 0.80 & 540 & $76.66 \pm 0.98$ & $74.04 \pm 0.59$ & $79.11 \pm 1.11$ & $780.11 \pm 2.54$ \\
\hline CG13 & $1: 3.45$ & 1.00 & 510 & $62.64 \pm 0.45$ & $61.23 \pm 1.29$ & $65.60 \pm 0.49$ & $832.30 \pm 8.41$ \\
\hline CG14 & $1: 3.45$ & 1.20 & 480 & $57.05 \pm 1.23$ & $57.55 \pm 0.95$ & $59.87 \pm 1.04$ & $793.15 \pm 7.48$ \\
\hline CG15 & $1: 3.45$ & 1.20 & 540 & $80.48 \pm 0.84$ & $78.13 \pm 1.30$ & $79.66 \pm 0.65$ & $744.66 \pm 6.89$ \\
\hline
\end{tabular}

Each data is expressed as mean $\pm \mathrm{SD}(n=3)$

$\% D E E$ percentage of drug entrapment efficiency

$p<0.01$ 
Table II. Degree of Hydration and Erosion Studies, \% Mucoadhesion, and Physical Characterization of Formulated Microparticles

\begin{tabular}{|c|c|c|c|c|c|c|}
\hline \multirow[t]{3}{*}{ Batch code } & \multicolumn{4}{|c|}{ Hydration index (HI) up to $9.5 \mathrm{~h}$ and erosion index (EI) 9.5 to $16 \mathrm{~h}$ at $37 \pm 1^{\circ} \mathrm{C}$} & \multirow{2}{*}{\multicolumn{2}{|c|}{$\frac{\% \text { Mucoadhesion at } 37 \pm 1{ }^{\circ} \mathrm{C}(10 \mathrm{~h})}{\text { Ex vivo }}$}} \\
\hline & \multicolumn{2}{|c|}{$\mathrm{HI}$} & \multicolumn{2}{|c|}{ EI } & & \\
\hline & pH 1.2 & pH 7.4 & $\mathrm{pH} 7.4$ & pH 1.2 & $\mathrm{pH} 1.2$ & pH 7.4 \\
\hline CG1 & $2.15 \pm 0.18$ & $1.73 \pm 0.20$ & $0.05 \pm 0.001$ & $0.03 \pm 0.001$ & 48 & 24 \\
\hline CG2 & $3.35 \pm 0.45$ & $2.32 \pm 0.56$ & $0.18 \pm 0.007$ & $0.13 \pm 0.004$ & 78 & 52 \\
\hline CG3 & $3.00 \pm 0.65$ & $2.02 \pm 0.64$ & $0.13 \pm 0.003$ & $0.09 \pm 0.002$ & 70 & 42 \\
\hline CG4 & $2.32 \pm 0.26$ & $1.86 \pm 0.32$ & $0.06 \pm 0.002$ & $0.02 \pm 0.007$ & 50 & 26 \\
\hline CG5 & $3.61 \pm 0.12$ & $2.55 \pm 0.11$ & $0.22 \pm 0.011$ & $0.17 \pm 0.010$ & 86 & 60 \\
\hline CG6 & $2.62 \pm 0.63$ & $1.94 \pm 0.26$ & $0.08 \pm 0.007$ & $0.05 \pm 0.005$ & 58 & 30 \\
\hline CG7 & $2.03 \pm 0.29$ & $1.52 \pm 0.44$ & $0.04 \pm 0.001$ & $0.04 \pm 0.004$ & 42 & 18 \\
\hline CG8 & $2.71 \pm 0.12$ & $1.83 \pm 0.17$ & $0.12 \pm 0.005$ & $0.07 \pm 0.006$ & 62 & 36 \\
\hline CG9 & $3.45 \pm 0.18$ & $2.37 \pm 0.78$ & $0.20 \pm 0.002$ & $0.16 \pm 0.008$ & 80 & 54 \\
\hline CG10 & $2.86 \pm 0.22$ & $2.03 \pm 0.21$ & $0.13 \pm 0.008$ & $0.08 \pm 0.007$ & 66 & 40 \\
\hline CG11 & $1.92 \pm 0.33$ & $1.22 \pm 0.09$ & $0.04 \pm 0.009$ & $0.02 \pm 0.003$ & 36 & 14 \\
\hline CG12 & $3.11 \pm 0.77$ & $2.16 \pm 0.49$ & $0.15 \pm 0.010$ & $0.11 \pm 0.005$ & 72 & 44 \\
\hline CG13 & $2.49 \pm 0.28$ & $1.89 \pm 0.32$ & $0.07 \pm 0.004$ & $0.04 \pm 0.002$ & 54 & 28 \\
\hline CG14 & $2.00 \pm 0.76$ & $1.37 \pm 0.12$ & $0.04 \pm 0.006$ & $0.02 \pm 0.007$ & 38 & 16 \\
\hline CG15 & $3.26 \pm 0.29$ & $2.32 \pm 0.56$ & $0.17 \pm 0.005$ & $0.12 \pm 0.001$ & 74 & 48 \\
\hline
\end{tabular}

Data represents mean $\pm \mathrm{SD}(n=3)$ $p<0.05$

Swelling kinetic (at pH 1.2) curves were plotted (Fig. 1) in which some important features of $\mathrm{CP}$ had been noted where some of the profiles were displayed. Some batches of formulations (CG2, CG5, CG9, CG12, and CG15) promptly got hydrated, and the maximum swellability of CG5 with respect to the other formulations was observed which swelled at a faster rate after $4 \mathrm{~h}$, whereas CG7, CG11, and CG14 trailed behind. In the case of CG1, CG6, CG7, CG10, CG11, CG13, and CG14, swelling rate up to $2 \mathrm{~h}$ was significantly poor. Kinetics of swelling of profiles at $\mathrm{pH} 7.4$ revealed that all formulations were least swellable initially up to $2-3 \mathrm{~h}$, and the swellability (HI) of CG7, CG11, and CG14 had declined after $7 \mathrm{~h}$. Swelling of particles depends upon the characteristics of the polymer, the medium, and the porosity of the particle. Particles became porous when the entrapped solvent (acetone, dehydrating agent) diffuses out faster through tortuous paths at higher revolutions per minute (540). There is more possibility of water absorption through these micropores facilitating the gelling ability of carbopol.

Both hydration (HI) and erosion studies (ES) by gravimetrical analysis showed its relative importance in understanding the mechanism of drug release (37). The erosion (weight loss) kinetics of all batches follow a similar pattern with respect to the $\mathrm{pH}$ environment compared to that of mucoadhesion. After a certain swelling period, the hydrated/ swollen mass started eroding slowly initially up to $2-3 \mathrm{~h}$. Afterwards, erosion was enhanced exponentially with time. In acidic $\mathrm{pH}$ (1.2), erosion rate was found slightly higher than that at $\mathrm{pH}$ 7.4. We observed that particles of low hydration index and erosion index possibly have lesser porosity. Porosity
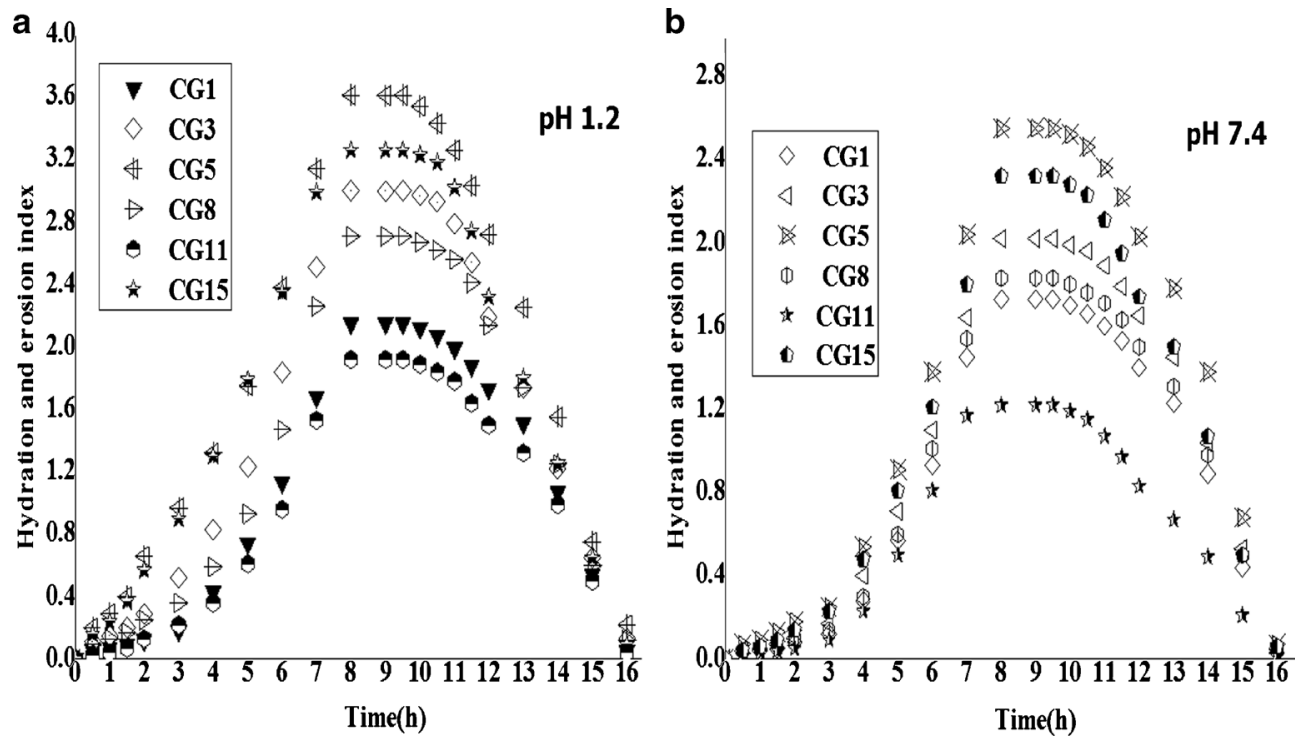

Fig. 1. Study of HI\% (gain) and EI\% (loss) of GLP-CP934P microbeads in a $\mathrm{pH} 1.2$ and $\mathbf{b} \mathrm{pH} 7.4$ 
can be controlled by controlling the following process variables: type of polymer, amount of polymer, and speed of rotation.

Carboxyl groups in the polymer CP934P bind more strongly with the oligosaccharide chains of mucin owing to hydrogen bonding, and thus, mucoadhesive force is enhanced $(38,39)$. The study of ex vivo mucoadhesion in Wistar rat confirmed that most of the formulations had good mucoadhesive strength in two different $\mathrm{pH}$ values (simulated gastric fluid (SGF) and simulated intestinal fluid (SIF)). The $\mathrm{pH}$ of the medium plays a critical role in controlling the degree of hydration, solubility, and mucoadhesion (40). It was observed (Table II) that mucoadhesion was comparatively higher in acidic $\mathrm{pH}(\mathrm{CG} 5,86 \%)$ than that in intestinal $\mathrm{pH}$ $7.4(60 \%)$. It suggests that CG5 formulation interacted greatly with the mucosubstrate on the surface of the stomach and adhered to the mucosa more strongly and could stay in the stomach for a prolonged period of time owing to higher HI. A similar effect of $\mathrm{pH}$ on mucoadhesivity of the polymer was reported by Belgamwar et al. (28). Maximum adhesion occurred when functional groups of polymer molecules were mostly in an undissociated state at $\mathrm{pH}<\mathrm{p} K_{\mathrm{a}}((14,15) ; \mathrm{BF}$ Goodrich brochure). The force required for detachment of particles from the mucus is much higher in lower acidic $\mathrm{pH}$ (41). The polymer may adhere better at acidic $\mathrm{pH}\left(<\mathrm{p} K_{\mathrm{a}} \sim 5.9\right)$ levels where they are partly in a protonated condition and unionized state. Above $\mathrm{pH}>\mathrm{p} K_{\mathrm{a}}$, the carboxylic acid groups are ionized to a greater extent, thus reducing hydrogen bond formation.

The ex vivo absorption study showed prolonged adhesivity of beads on the treated membrane, whereas these results cannot be mimicked in in vivo conditions which is influenced by many factors such as the presence of food, peristaltic motion of the GIT, the presence of the mucous layer and periodical washing off of the mucosal layer from the gastric membrane, and replacement by a new secretion. Therefore, prolonged adherence (till $10 \mathrm{~h}$ ) of the mucoadhesive particles cannot be assured or extrapolated to in vivo experiments. But it was expected to be lengthened because of mucoadhesivity as suggested by the ex vivo test. Of course, the residence period of microbeads in the whole GIT was prolonged (18 h) as supported by the hypoglycemic activity of microbeads in the animal model. It suggested that the drug was released from major fractions of the microbeads in adhesioned state and some in the nonadhesioned state. In vitro release studies were carried out maintaining the standard protocol of dissolution. Drug release was extended till $18 \mathrm{~h}$ as we observed in formulation CG5. Moreover, there was an indirect indication that the drug-loaded beads showed higher efficacy owing to its adhesion to the gastric/intestine membrane than that of other varieties as we observed in in vivo studies (percentage decrease of glucose level). To be assured about the adhesion/stability of the beads in in vivo experiments, a large number of animals are to be sacrificed at different time intervals to assess visually the adherence of beads on the mucous membrane of the GIT. The protocol of animal experimentation restricts the random use of animals according to the Animal Ethical Committee. The present study dealt with the suitability of CP934P in the development of a controlled release drug delivery of the antidiabetic drug
GLP. The same polymer had been utilized by many investigators to develop dosage forms of various types of drug moieties with different solubility, basicity, and stability, and its research is ongoing. For example, previously, Patel and Chavda (12) and Patel et al. (13) investigated on similar types of works using combinations of two polymers carbopol 934P and ethyl cellulose. The reported "drug entrapment efficiency" in microspheres $\left(d_{\mathrm{p}} \sim 109 \mu \mathrm{m}\right)$ was sufficiently poor leading to loss of costly drugs during preparation of microparticles. It is very important to select a polymer on the basis of the characteristics of drugs and other chemical variables controlling the solvent evaporation method in order to avoid poor yield and loss of costly drugs. Whether the developed product is economically viable for costly drug materials or not, it should be of prime concern before the final selection of materials. If the microparticles were very fine $(\sim 109 \mu \mathrm{m})$, it may create difficulty in performing ex vivo mucoadhesivity test while counting particles that adhered to the membrane. In the present study, we observed that the entrapment of GLP was satisfactory $(89.45 \%)$. The average particle size of the best batch of the product was $714.56 \pm 9.70 \mu \mathrm{m}$.

\section{Study of Drug Release}

The study of drug release was performed for all 15 combinations of formulations. Few of the release profiles (formulation codes CG5, CG6, CG9, CG10, CG12, and CG15) were displayed in Fig. 2. The cumulative percentage of drug release depends on various factors, such as the properties of the drug $(\log \mathrm{P}, 2.5)$ and polymer viscosity $(35,000-39,400 \mathrm{mPa}$ ), polymer chemistry, particle size $\left(d_{\mathrm{p}}\right)$ and its internal porosity, operating temperature, preparation method, and physicochemical property of the dissolution medium. Pure GLP is a weak acid $\left(\mathrm{p} K_{\mathrm{a}}, 5.9\right)$ and its solubility increases with the rise in $\mathrm{pH}$ (saturation solubility of GLP at $\mathrm{pH} 7.4$ and $\mathrm{pH} 1.2$ is $7.21 \mathrm{mg} / 100 \mathrm{ml}$ and $3.66 \mathrm{mg} / 100 \mathrm{ml}$ at $25^{\circ} \mathrm{C}$, respectively). Verma and Garg (40) reported similar data on the solubility of GLP in SIF as $7.8 \mathrm{mg} / 100 \mathrm{ml}$ at $37^{\circ} \mathrm{C}$. Drug release was studied at $\mathrm{pH} 1.2$ for the first $2 \mathrm{~h}$ and continued till $18 \mathrm{~h}$ at 37 $\pm 0.5^{\circ} \mathrm{C}$ in $\mathrm{PBS}, \mathrm{pH} 7.4$. The cumulative percentage release varied in the range of $57.05-96.83 \%$ depending on the controlling variables $(\times 1, \times 2$, and $\times 3)$. Although a sustained effect was observed in all formulations, a satisfactory completion of release $(\sim 96 \%)$ was depicted by the profile of CG5. Many batches of formulations showed steady release up to $18 \mathrm{~h}$ (CG9, CG10, CG12, and CG15), and no further increase in release percentage was observed (not displayed in the figure). Incomplete drug release was observed too in the case of CG4, CG13, CG6, and CG11 which were nearly 42-67\% in $16 \mathrm{~h}$. The release rate of GLP at lower $\mathrm{pH}$ (acidic) of the dissolution medium was found low enough as the solubility of the drug was low. The rate of swelling of particles $(\mathrm{pH} 1.2)$ was low during the first 2-3 h. In Fig. 2, it was explicitly shown that the release rate increased sharply after $3 \mathrm{~h}$ of onset of release when the rate of swelling ( $\mathrm{pH}$ 7.4) onwards was observed to be high. The characteristics of profiles may be explained as a reduced rate of release occurred in the first $2 \mathrm{~h}$ owing to low solubility of the drug at low $\mathrm{pH}$ which mimics the $\mathrm{pH}$ of the stomach, the compact association of polymeric chains, and the poor penetration rate of water molecules within particles during the initial $2-3 \mathrm{~h}$. Unlike in acidic $\mathrm{pH}$, the release rate was 


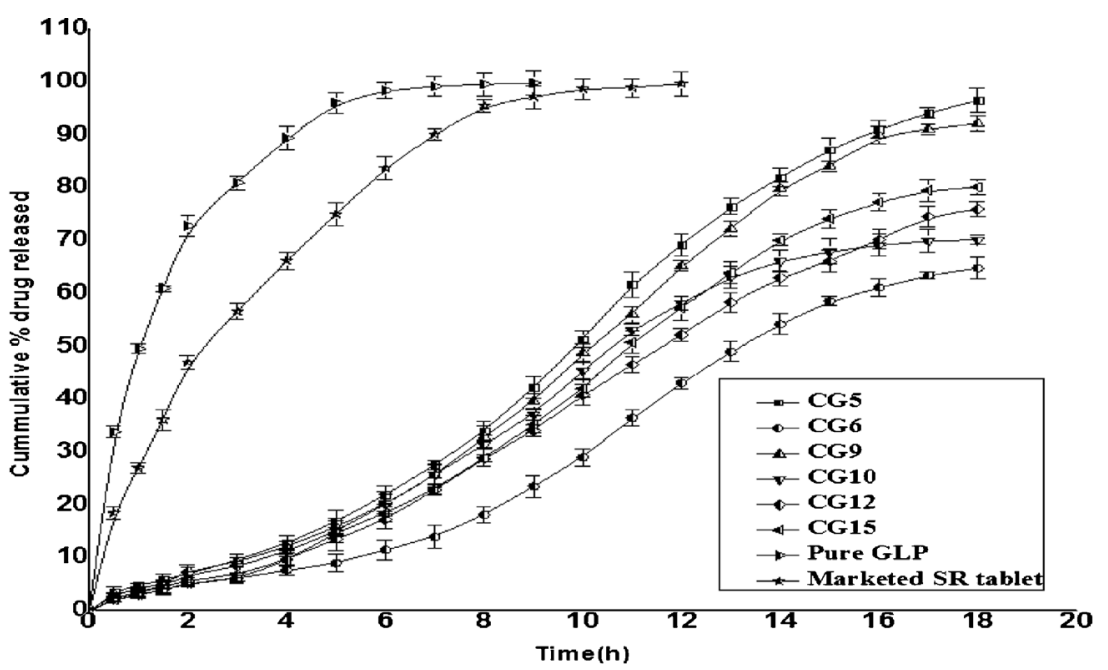

Fig. 2. Comparison of dissolution profiles for pure GLP, marketed SR tablet, and mucoadhesive microbeads of GLP-CP934P

much higher after $2 \mathrm{~h}$ onwards in $\mathrm{pH}$ 7.4. It may be explained that as the solubility of the drug is higher at $\mathrm{pH}>\mathrm{p} K_{\mathrm{a}}$, carboxylate ions of polymeric chains repel each other facilitating the penetration of water and subsequent gradual erosion of polymeric phase which led to a faster release of the drug too. Maximum amount of the drug was released from batch CG5 which was followed by that from CG9 and CG2. When pure drug was added to the dissolution medium and its release was controlled solely by the diffusion and solubility of the drug, as there is no physical barrier to the diffusion of the powdered drug, so its release rate was not controlled. In the case of the marketed SR tablet, the release was $>90 \%$ within $8 \mathrm{~h}$. Its release rate was much higher in acidic medium (first $2 \mathrm{~h}$ ) as the stirring rate was enough to disperse the powdered sample of the tablet and the release was continued till $8 \mathrm{~h}$. Afterwards, it slowed down further till $12 \mathrm{~h}$ in $\mathrm{pH}$ 7.4. As the detailed composition for the marketed SR product is not revealed by the manufacturer, it is assumed that some added solubilizing agent and dispersant might have facilitated water penetration and caused a high release of the drug in the dissolution medium ( $\mathrm{pH}$ 1.2). Because a small quantity of the drug was used to study drug release, so the intact tablet of the marketed product could not be used. In this case, the release of the drug was not retarded as much as that of the newly developed GLP formulation (CG5). It was observed that $97.27 \pm 2.19 \%$ GLP was released within $9 \mathrm{~h}$ from the sample powder of the marketed SR tablet, whereas 69.31 $\pm 1.98 \%$ of the drug was released in a 12 -h period from the prepared formulation (CG5) and the release of the drug was extended up to $18 \mathrm{~h}$. The prepared formulation was found to be more effective than the available marketed product. Dissolution profiles have a similarity as evidenced from the similarity factor, $f_{2}$. Using pure GLP as a reference substance, this factor is $\sim 92 \%$ both for the marketed SR tablet and formulation CG5.

In 2009, Hosmani et al. (2) optimized SR microspheres of glipizide by using the factorial design method and reported the effect of the combinations of polymers (polycarbophil and sodium alginate) on drug entrapment $(75 \%)$, yield $(97 \%)$ swelling index (2.2), and mucoadhesion $(100 \%)$, and the release of the drug was extended up to a period of $8 \mathrm{~h}$. It showed a hypoglycemic effect by the oral glucose tolerance test (OGTT) test for a period of 1-9 h. Behera et al. (42) prepared microspheres of glipizide with polymethacrylate and observed dissolution of the drug in alkaline $\mathrm{pH}$ and reported that the release of the drug was extended up to $8 \mathrm{~h}$. There are some reports on the prolonged release of GLP from microspheres up to $24 \mathrm{~h}(33,43,44)$ in which the method of preparation of the products was quite time consuming and expensive in comparison with that of the present investigation.

The controlling parameters (Table I) made a complex effect on the average size of particles $\left(d_{\mathrm{p}}\right)$ and other responses (yield, entrapment, cumulative percentage release). With increasing amount of the polymer, the dispersed system turned to be more viscous in nature. In this situation, the stirring effect played an important role, keeping emulsion droplets in a suspended state and facilitating the quick removal of the solvent and solidification of the droplets. The percentage loss of materials during preparation was accounted owing to either production of very fine particles or faster rate of settling of viscous droplets before solidification occurred. In this regard, droplet sizes, viscosity of dispersed phase, and density difference between two phases have effects on the percentage yield of the products which can be efficiently controlled by proper selection of the process parameters. By analyzing data (Table I), the decrease of percentage drug release that occurred was evident when polymer quantity was increased as observed in various formulations: CG1, CG11; CG2, CG12; CG3, CG8, CG13; CG4, CG10, CG14; and CG5, CG15, at a fixed concentration of the surface active agent $\left(X_{2}\right)$ and stirring rate $\left(X_{3}\right)$. Percent yield and DEE were increased with increasing polymer content and stirring rate. The average particle size $\left(d_{\mathrm{p}}\right)$ was higher at a higher polymer content and at a lower concentration of SA (CG7, CG10, CG6, CG8), but the stirring effect might have caused lessening of average particle size in some cases. Total interfacial surface area of a batch of particles is an important parameter which is controlled by stirring speed, polymer content, and concentration of the surface active agent.

The mechanism of drug release from the mucoadhesive microbeads may be due to diffusion phenomena, and erosion effects may be dominant in the latter part or due to a 
Table III. Release Kinetics Parameters of Some Selected Formulations

\begin{tabular}{|c|c|c|c|c|c|c|c|c|}
\hline \multirow[t]{2}{*}{ Batch code } & \multicolumn{2}{|c|}{ Zero order } & \multicolumn{2}{|c|}{ First order } & \multicolumn{2}{|c|}{ Higuchi } & \multicolumn{2}{|c|}{ Korsmeyer-Peppas } \\
\hline & $R^{2}$ & $k_{0}$ & $R^{2}$ & $k_{1}$ & $R^{2}$ & $k_{\mathrm{h}}$ & $R^{2}$ & $n$ \\
\hline CG5 & 0.956 & 5.008 & 0.924 & -0.033 & 0.913 & 24.68 & 0.963 & 0.365 \\
\hline CG6 & 0.929 & 2.680 & 0.896 & -0.014 & 0.853 & 12.84 & 0.918 & 0.498 \\
\hline CG9 & 0.951 & 4.704 & 0.918 & -0.030 & 0.899 & 23.02 & 0.954 & 0.488 \\
\hline CG10 & 0.962 & 4.473 & 0.942 & -0.028 & 0.921 & 21.97 & 0.969 & 0.491 \\
\hline CG12 & 0.958 & 4.085 & 0.946 & -0.025 & 0.919 & 20.25 & 0.968 & 0.376 \\
\hline CG15 & 0.960 & 4.247 & 0.952 & -0.026 & 0.930 & 21.27 & 0.975 & 0.133 \\
\hline
\end{tabular}

combination of both processes (45). The data from the in vitro study was fitted to various kinetic models to determine the kinetics of drug release from the microspheres of GLP-CP934P. The coefficients of regression and the release rate constant values were computed in Table III. The data were fitted well to the zero-order kinetics $\left(R^{2}=0.929-0.962\right)$ with the slope value $\left(k_{0}\right)$ ranging from 2.680 to 5.008 as well as to the Korsmeyer-Peppas model. It indicated coupling of the "diffusion" and "erosion" mechanism in drug release which is attributed to swelling of particles in different biological fluids (SGF or SIF) and erosion in later part. Previous reports on the different mechanisms of the release of GLP indicated its dependence on the characteristics of different systems $(27,43,46-48)$.

From various characteristic data, we suggest CG5 as the satisfactory formulation providing prolonged residence time, HI, and high percentage of drug release till a longer period. Further confirmatory studies were performed with CG5. The stability of formulation CG5 was tested at various conditions. GLP microbeads (CG5) stored at 4 $\pm 1^{\circ} \mathrm{C}, 25 \pm 2^{\circ} \mathrm{C}$ and $60 \pm 5 \% \mathrm{RH}$ and $37 \pm 2^{\circ} \mathrm{C}$ and $65 \pm 5 \%$ RH for 90 days showed drug release of $96.41 \pm 1.56 \%$, $96.30 \pm 2.35 .40 \%$, and $96.91 \pm 1.77 \%$, respectively. Initially, the same formulation showed $96.59 \pm 2.33 \%$ release of the drug. The result indicated that formulation CG5 is expected to be stable during its shelf life.

\section{Solid-State Studies}

The FTIR spectra of pure GLP, CP934P, and formulation microbeads (CG5) were recorded between 400 and $4000 \mathrm{~cm}^{-1}$ in Fig. 3. The spectrum of pure GLP showed various absorption bands at $3325.28 \mathrm{~cm}^{-1}$ and $3290.05 \mathrm{~cm}^{-1}$ (NH stretching), $2943.56 \mathrm{~cm}^{-1}$ and $2854.83 \mathrm{~cm}^{-1}$ (CH stretching), $1597.12 \mathrm{~cm}^{-1}$ (CO in $\mathrm{NH}$ bending), $1683.56 \mathrm{~cm}^{-1}$ ( $\mathrm{NH}$ bending), and $1444.08 \mathrm{~cm}^{-1}$ ( $\mathrm{CH}$ bending) in crystalline form. The important absorption bands of pure GLP also matched with those observed in the spectrum of formulation CG5, indicating the stable nature of the drug during encapsulation. From the FTIR spectra, it was confirmed that GLP and the formulation component were compatible with each other.

The diffractogram patterns of pure GLP showed the important crystallographic characteristics at different scattering angles from $5^{\circ}$ to $30^{\circ}(2 \theta)$ with different signal intensities (49). The diffractogram corresponding to pure CP934P showed a halo pattern of its amorphous nature. In the XRD of the microbeads, multiple sharp peaks were recorded corresponding to pure drug along with some halo pattern corresponding to the polymer. Reduction in intensity of the drug molecule's peaks was observed (Fig. 4) which might be due to its smaller fraction in the combination of drug and polymer. This explicitly indicated that no interaction of the drug with the polymer occurred owing to encapsulation.

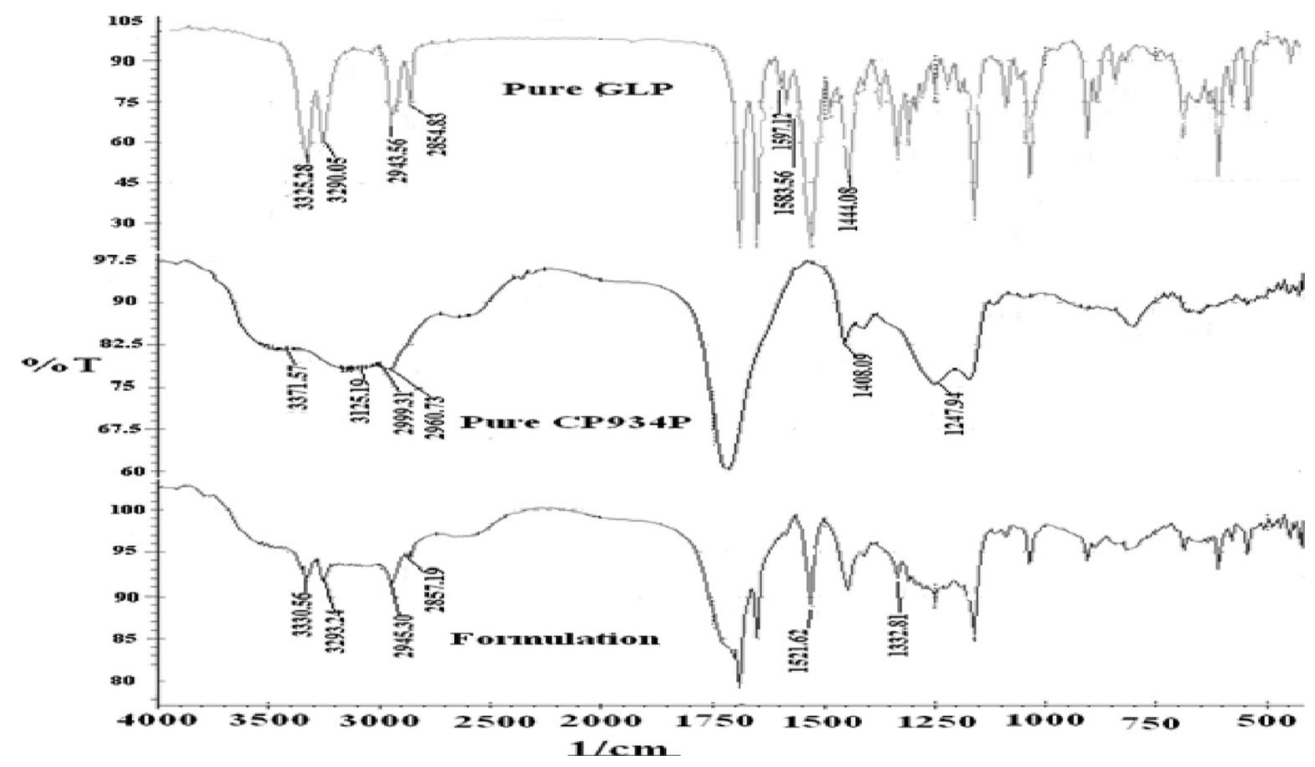

Fig. 3. FTIR spectra of pure GLP, pure CP934P, and formulated microbeads (CG5) 


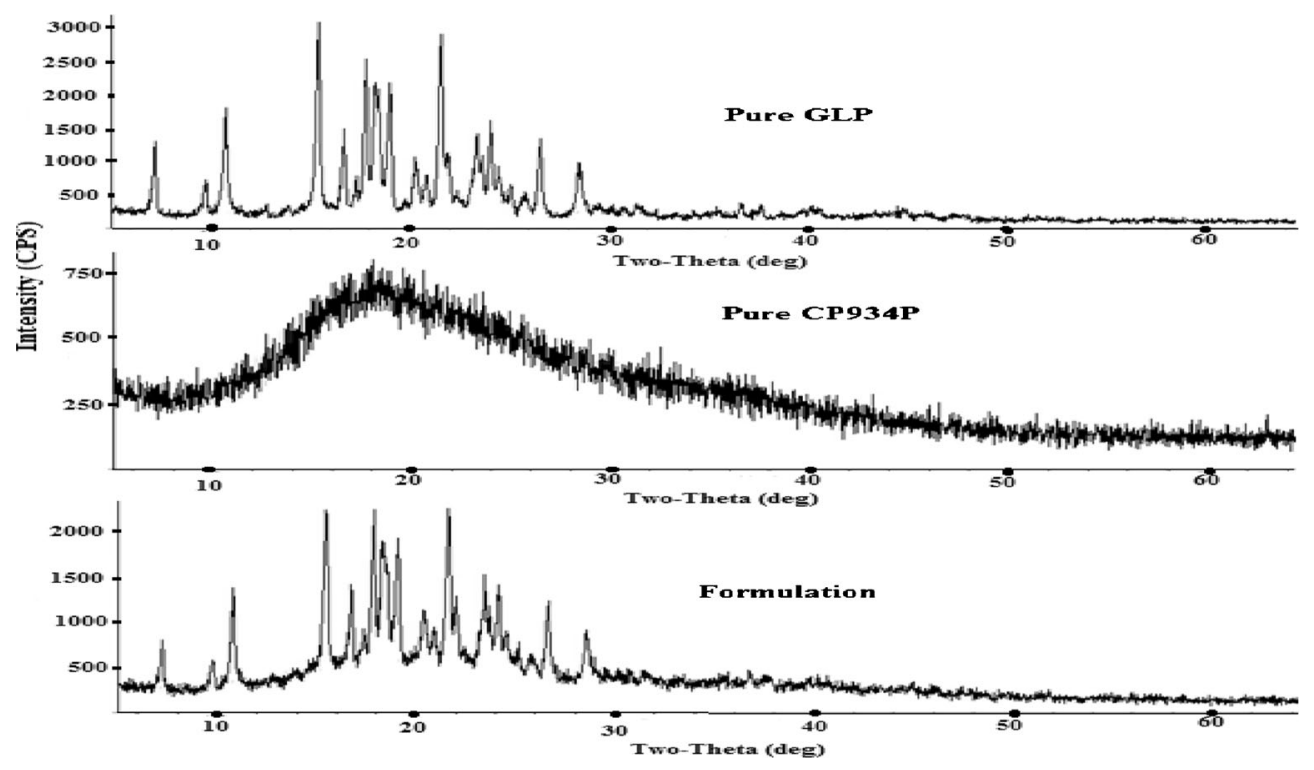

Fig. 4. X-ray powder diffraction spectra of pure GLP, pure CP934P, and formulated microbeads (CG5)

Interaction between the pure component and other excipients may be illustrated by differential scanning calorimetry by changes in the thermal events, such as elimination of an endotherm or exotherm peak or appearance of a new peak owing to mixing of the components without indicating any significant interaction. If all thermal features more or less remain the same, compatibility can be expected as well as there is a possibility of no complex formation. A sharp endothermic peak of pure GLP was reported earlier at $203^{\circ} \mathrm{C}(49)$ owing to its melting transition point which we observed at $207.55^{\circ} \mathrm{C}$ (Fig. 5). No endothermic deflection was visible in the flat DSC profile of CP934P because of its amorphous state. A feeble peak corresponding to the melting point of GLP was observed in the DSC profile of the microbeads. GLP was present in a smaller amount so its fusion peak might have been masked almost by the strong exothermic effect which is attributed to the decomposition of the polymer. Thus, the quantity of material used may affect the visibility of the peak, shape, and enthalpy, and this might not necessarily indicate potential incompatibility.

\section{Morphology of the Microbeads}

Scanning electron microscopy revealed that the surface of selected microbeads is uneven and apparently dense (Fig. 6a-c). After dissolution, its surface becomes apparently porous owing to erosion of the surface material (Fig. 6b, d). It supports that drug release from microparticles was attributed to diffusion and subsequent erosion mechanism.

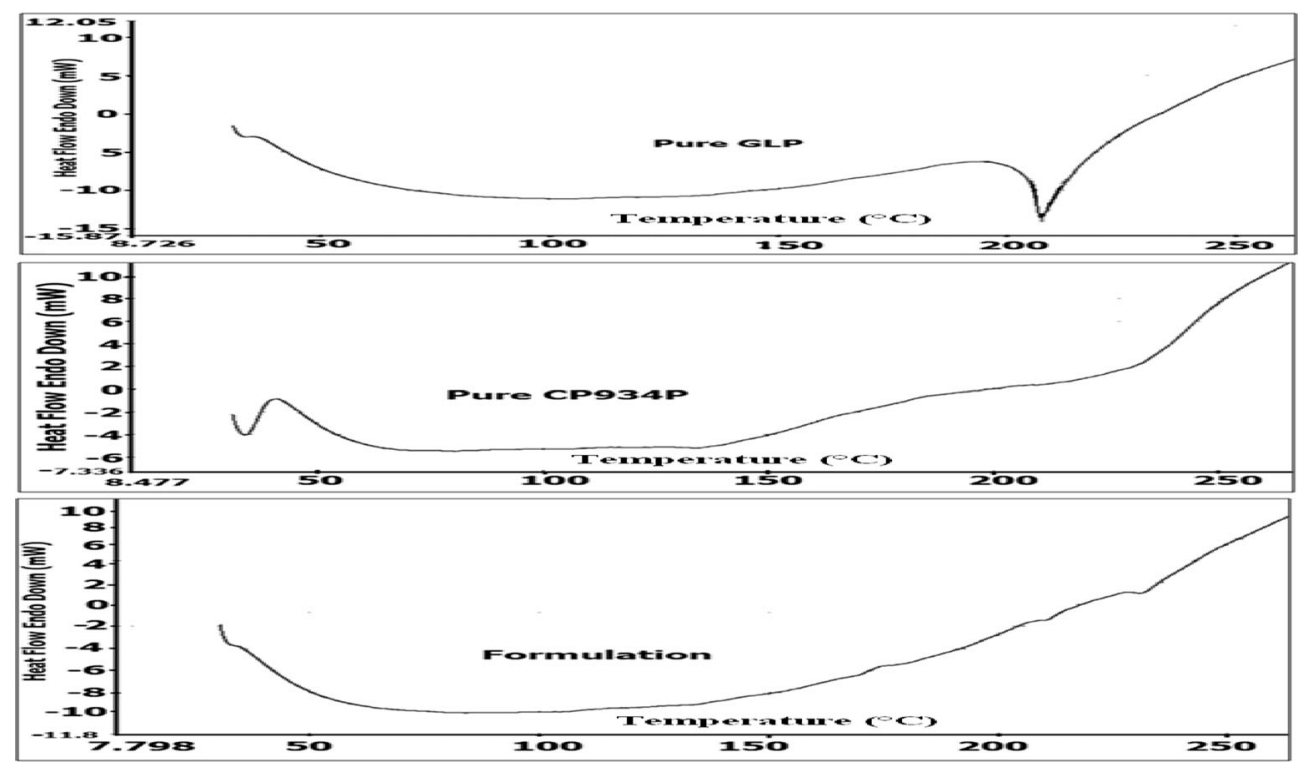

Fig. 5. DSC thermograms of pure GLP, pure CP934P, and formulated microbeads (CG5) 

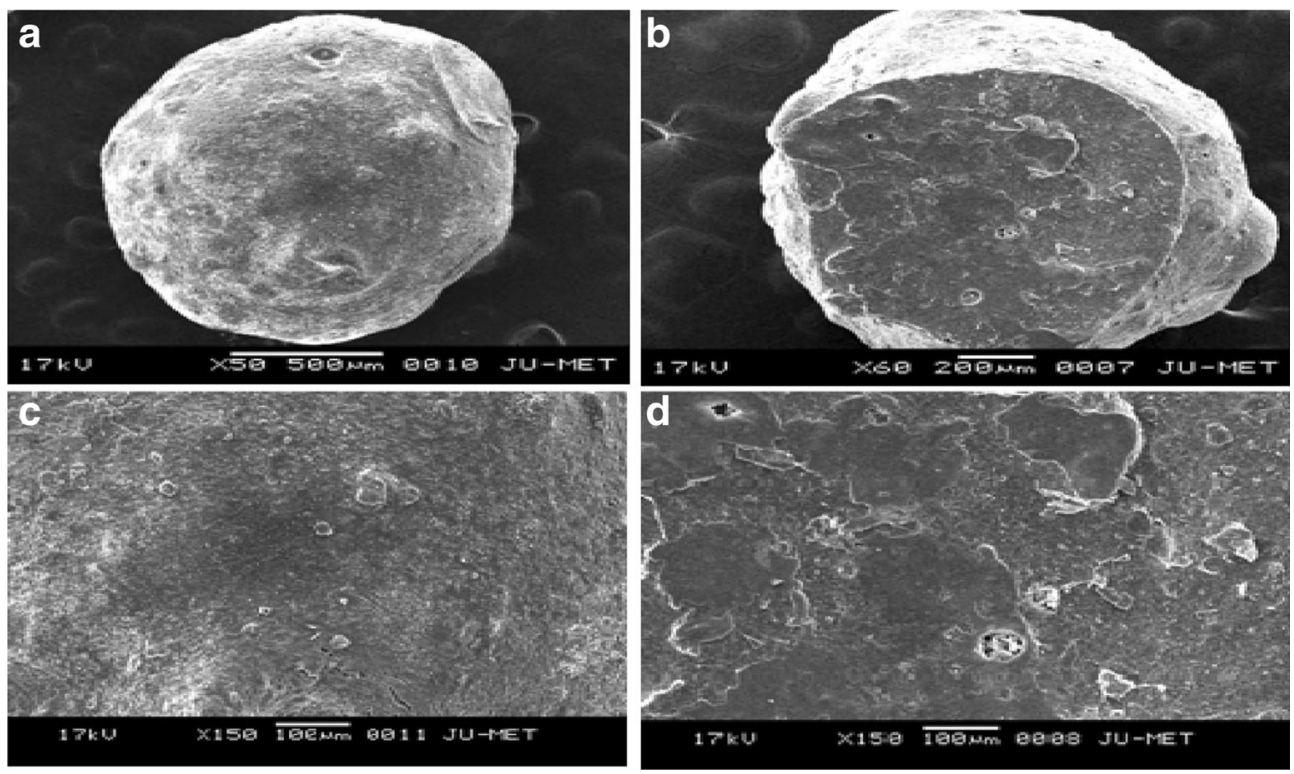

Fig. 6. SEM micrographs of the microbeads (CG5). a Before dissolution. b After dissolution. c Surface before dissolution $(\times 150)$. d Surface after dissolution $(\times 150)$

\section{Acute Toxicity Test}

The oral administration of new formulations at a dose of $5 \mathrm{mg} / \mathrm{kg}$ of body weight of rats did not cause any significant sign of toxicity or change in gross behavioral pattern during the specified period. It showed no lethal effect to any animal under the experimental conditions. It is suggested that the new formulation CG5 is safe as a sustained release dosage form.

\section{Ex Vivo Absorption Study in a Goat Intestine Segment}

Permeability and solubility of a drug at the site of absorption in the system are two important considerations in maximizing the bioavailability of a drug administered orally. The extent of absorption in vivo thus can be predicted on the basis of an ex vivo study of the permeability of the drug through the membrane and the solubility of a particular drug (50). A section of goat intestine obtained from an already slaughtered animal from a local store had been used to perform the ex vivo absorption study. It is less expensive and fast and it does not require prior permission from the Animals Ethical Committee. We observed that $\sim 89-97 \%$ (of the initial dose) of the drug was released from microbeads after $18 \mathrm{~h}$ of study, and the distribution pattern of GLP was as follows for batch CG5: in the liquid of the mucosal compartment (b, $65.56 \%$ ) and within the intestinal mucosal membrane (c, $22.01 \%$ ), serosal compartment (a, $\sim 10 \%$ ), and residual amount of GLP in the microbeads (d, $1.86 \%)$. The results of some formulations (CG5, CG6, CG9, CG10, CG12, and CG15) are shown in Table IV. In mass balance calculation (Table IV), $\sim 99-100 \%$ of GLP was found accountable. In vitro study of the drug release of CG5 in PBS 7.4 was observed as $\sim 97 \%$ of the drug after $24 \mathrm{~h}$. A maximum amount was distributed in the mucosal compartment (b) and a lesser amount $(\sim 10 \%)$ was observed in the serosal compartment, whereas $58 \%$ of GLP was permeated into the serosal compartment in the case of pure glipizide. It indicated a slow release of the drug from the

Table IV. Study of Mass Balance of GLP in the Ex Vivo Absorption Experiment

\begin{tabular}{|c|c|c|c|c|c|}
\hline \multirow[t]{2}{*}{ Batch code } & \multicolumn{5}{|c|}{$\%$ of drug in $\mathrm{pH} 7.4 \mathrm{PBS}(24 \mathrm{~h})$} \\
\hline & $\begin{array}{l}\text { Serosal } \\
\quad \text { compartment (a) }\end{array}$ & $\begin{array}{l}\text { Mucosal } \\
\text { compartment (b) }\end{array}$ & $\begin{array}{l}\text { Intestinal } \\
\text { membrane (c) }\end{array}$ & $\begin{array}{l}\text { Residual amount of } \\
\text { GLP in microbeads (d) }\end{array}$ & $\begin{array}{l}\text { Total recovery of } \\
\qquad \operatorname{GLP}(\mathrm{a}+\mathrm{b}+\mathrm{c}+\mathrm{d})\end{array}$ \\
\hline CG5 & $10.28 \pm 0.81$ & $65.56 \pm 2.09$ & $22.01 \pm 0.99$ & $1.86 \pm 0.16$ & 99.71 \\
\hline CG6 & $14.01 \pm 0.77$ & $56.22 \pm 3.44$ & $18.25 \pm 0.35$ & $10.33 \pm 1.10$ & 98.81 \\
\hline CG9 & $13.81 \pm 0.91$ & $57.73 \pm 1.65$ & $18.90 \pm 0.67$ & $8.93 \pm 0.77$ & 99.37 \\
\hline CG10 & $12.67 \pm 0.65$ & $60.14 \pm 4.12$ & $20.36 \pm 1.23$ & $6.11 \pm 0.33$ & 99.28 \\
\hline CG12 & $13.56 \pm 0.19$ & $58.31 \pm 1.22$ & $19.05 \pm 1.11$ & $8.19 \pm 0.79$ & 99.11 \\
\hline CG15 & $15.26 \pm 0.47$ & $55.37 \pm 0.98$ & $18.05 \pm 0.81$ & $11.07 \pm 1.67$ & 99.75 \\
\hline Pure GLP (control) & $58.14 \pm 1.26$ & $19.77 \pm 0.97$ & $20.49 \pm 0.76$ & $0.91 \pm 0.09$ & 99.31 \\
\hline
\end{tabular}

Mean \pm SD $(n=4)$

$G L P$ glipizide, $P B S$ phosphate buffered saline $p<0.01$ 


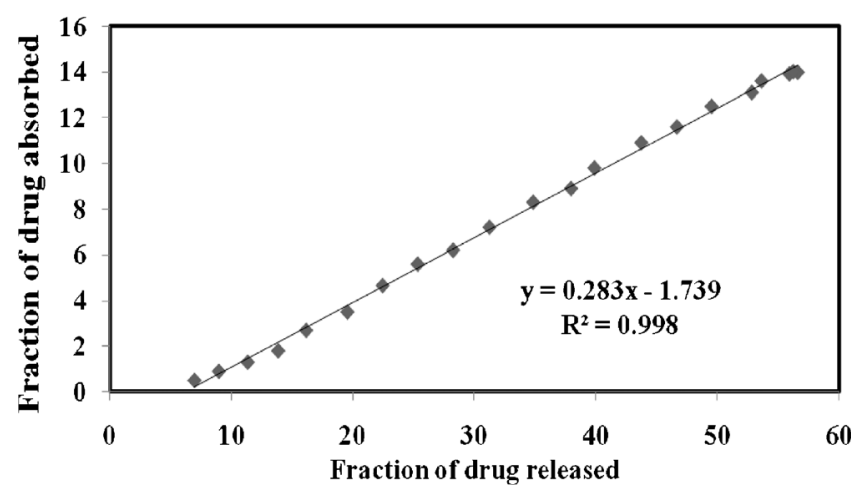

Fig. 7. Fraction of the drug released $v s$. fraction of the drug absorbed (CG5)

microbeads in comparison with that of the pure drug which has less aqueous solubility $(7.21 \mathrm{mg} / 100 \mathrm{ml}$ in $\mathrm{pH}$ 7.4) but high permeability. Total amount permeated depends on the area of permeation too. The experiment was conducted also in everted intestinal segment as designed by Kale et al. (51). The result was approximately the same as that of a previous one. The permeation rate followed the zero-order kinetics. A correlation $\left(R^{2}=0.998\right)$ was established by plotting the fraction of GLP absorbed against the fraction of GLP released from microbeads (CG5) in Fig. 7.

\section{Oral Glucose Tolerance Test}

Oral glucose tolerance test was carried out to find out how quickly GLP was removed from the plasma level of Wistar rat and guinea pig. When pure GLP was administered orally to a group of animals, a rapid reduction in blood glucose levels was observed, and a maximum reduction of $58.44 \pm 0.66$ and $59.02 \pm 1.04 \%$ was observed in Wistar rat and guinea pig, respectively, at $2 \mathrm{~h}$ (Fig. 8). In the case of the marketed SR tablet, it was fed to the animals as a powdered sample and the lowering of the glucose level reached a maximum level at $5 \mathrm{~h}$ $(50.67 \pm 2.00 \%$, rat and $51.04 \pm 2.34 \%$, guinea pig). But in the case of CG5, the lowering of the glucose level was gradual and reached a maximum reduction of glucose level of 43.03 $\pm 1.06 \%$ and $44.04 \pm 1.90 \%$ at $5 \mathrm{~h}$, respectively, and sustained for a long period. A $25 \%$ reduction in glucose level is considered significant for a hypoglycemic effect (52). Reduction of blood glucose levels in Wistar rat was compared with that in the guinea pig model. In vivo testing of CG5 in Wistar rat and guinea pig demonstrated a significant hypoglycemic effect of the new formulation, and a more pronounced and prolonged effect beyond $12 \mathrm{~h}$ than that of the marketed product; hence, it was better suited for oral sustained release formulation. From the results of the Student's $t$ test, a significant difference was observed among the hypoglycemic activity of pure GLP, marketed SR tablet, and CG5 microbeads $(p<0.01)$. Madhusudhan et al. (32) had reported a similar prolonged effect with GLP microparticles of Eudragit RS 100 and Eudragit RL 100 but reported that the method of preparation of the microspheres was considered lengthy and expensive.

\section{CONCLUSION}

Sustained drug delivery systems are widely useful to provide constant and sustained therapeutic drug levels. These systems provide protection of the drug in the hostile environment of the upper GIT, avoid first-pass effects, increase patient compliance, and release the drug at a specific site. In the present study, the antidiabetic drug GLP-loaded mucoadhesive microbeads were prepared by the solvent evaporation technique by using polymer namely carbopol $934 \mathrm{P}$ as the release-retarding carrier, and the best batch formulation CG5 showed a sustained release for a longer period approaching nearly completion of release. The yield of product and \% DEE were satisfactorily high and the loss percentage during preparation was minimum. This batch (CG5) showed good HI (3.61 \pm 0.12$)$, long-lasting mucoadhesion (ex vivo, $86 \%$ ), and successful drug release $(96.83 \%)$ up to $18 \mathrm{~h}$. Maximum \% DEE and \% yield were recorded as $89.45 \%$ and $94.11 \%$, respectively.

In vivo studies in animal models evidenced a greater sustained effect in the lowering of glucose level from the blood plasma in the case of GLP microbeads (CG5) as compared to that of marketed SR tablets. Moreover, a single polymer (CP934P) was found sufficiently effective in retarding the release of the drug in vitro for a long period in the present study $(18 \mathrm{~h})$. Therefore, the method protocol as well as CP934P was aptly chosen to develop the controlled release

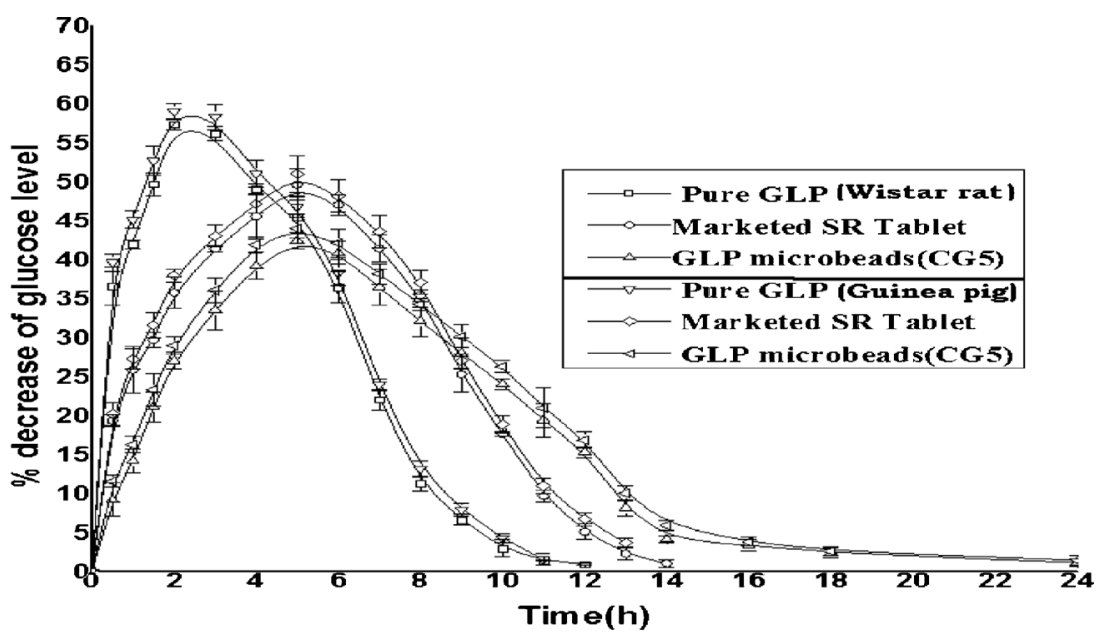

Fig. 8. In vivo glucose tolerance test of GLP in Wistar rat and guinea pig model 
of mucoadhesive beads of glipizide. With reference to other reported works, the present investigation has led to the development of a more effective dosage form for the antidiabetic drug glipizide using polymer CP934P. In conclusion, this investigation was an approach for targeting its release at its site of absorption owing to bioadhesion, sustaining its release and improving its oral bioavailability. It suggested that the use of CP934P as a mucoadhesive agent in a antidiabetic formulation is a novel one because its preparation method is very simple and less expensive.

\section{ACKNOWLEDGMENTS}

The authors acknowledge the cooperation provided by "Calcutta Institute of Pharmaceutical Technology \& AHS," Uluberia, West Bengal, India, and Jadavpur University, Pharmaceutical Technology.

\section{REFERENCES}

1. Sarode SM, Mittal M, Magar RM, Shelke AD, Shrivastava B, Vidyasagar G. Formulation and evaluation of floating microspheres of glipizide. J Chem Pharm Res. 2011;3:77583.

2. Hosmani AH, Kasture PV, Gonjari ID, Karmarkar AB. Study of formulation variables on properties of glipizide mucoadhesive microspheres by factorial design. DARU. 2009;17(4):236-44.

3. Swarbrick J, Boylan JC, editors. Encyclopedia of pharmaceutical technology. Boca Raton: CRC; 2000. p. 183-4.

4. Ponchel G, Touchard F, Duchene D, Peppas NA. Bioadhesive analysis of controlled release systems. I. Fracture and interpenetration analysis in poly(acrylic acid)-containing systems. J Control Release. 1987;5:129-41.

5. Vidgren P, Vidgren M, Arppe J, Hakuli T, Laine E, Paronen P. In vitro evaluation of spray-dried mucoadhesive microspheres for nasal administration. Drug Dev Ind Pharm. 1992;18:581-97.

6. Mortazavi A, Smart JD. An investigation into the role of water movement and mucus gel dehydration in mucoadhesion. J Control Release. 1993;25:197-203.

7. Vidgren P, Vidgren M, Vainio P, Nuutinen J, Paronen P. Double labeling technique in the evaluation of nasal mucoadhesion of disodium cromoglycate microspheres. Int J Pharm. 1991;73:1316.

8. Jelvehgari M, Milani PZ, Khonsari F. Comparative study of in vitro release and mucoadhesivity of gastric-compacts composed of multiple unit system/bilayered discs using direct compression of metformin hydrochloride. BioImpacts. 2014;4(1):2938.

9. Liu Z, Lu W, Qian LX, Zhang X, Zeng P, Pan J. In vitro and in vivo studies on mucoadhesive microspheres of amoxicillin. $\mathrm{J}$ Control Release. 2005;102:135-44.

10. Yellanki SK, Sing J, Syed JA, Bigala R, Goranti S, Nerella NK. Design and characterization of amoxicillin trihydrate mucoadhesive microspheres for prolonged gastric retention. Int J Pharm Sci Drug Res. 2010;2:112-4.

11. Kalyankar TM, Rangari NT, Khan M, Hosmani A, Sonwane A. Formulation and evaluation of mucoadhesive pioglitazone $\mathrm{HCl}$ microspheres. Int J Pharm World Res. 2010;1:1-13.

12. Patel JK, Chavda JR. Formulation and evaluation of stomachspecific amoxicillin-loaded carbopol-934P mucoadhesive microspheres for anti-Helicobacter pylori therapy. J Microencapsul. 2009;26(4):365-76.

13. Patel J, Patel D, Raval J. Formulation and evaluation of propranolol hydrochloride-loaded carbopol-934P/ethyl cellulose mucoadhesive microspheres. Iran J Pharm Res. 2010;9(3):221-32.

14. Chu JS, Yu DM, Amidon GL, Weiner ND, Goldberg AH. Viscoelastic properties of polyacrylic acid gels in mixed solvents. Pharm Res. 1992;9:1659-63.
15. Riley RG, Smart F, Tsiboukli DJ, Dettmar J, Hampson PW, Alf Davis $\mathrm{F}$, et al. An investigation of mucus/polymer rheological synergism using synthesized and characterised poly (acrylic acid). Int J Pharm. 2001;217:87-100.

16. Tamburic S, Craig DQM. Rheological evaluation of polyacrylic acid hydrogels. Pharm Sci. 1995;1:107-9.

17. Tamburic S, Craig DQM. An investigation into the rheological, dielectric and mucoadhesive properties of poly (acrylic acid). J Control Release. 1995;37:59-68.

18. Blanco-Fuente H, Anguiamo-Igea S, Otero-Espinar FJ, BlancoMendez J. In vitro bioadhesion of carbopol hydrogels. Int J Pharm. 1996;142:169-74.

19. Bonacucina G, Martelli S, Palmieri GF. Rheological, mucoadhesive and release properties of carbopol gels in hydrophilic cosolvents. Int J Pharm. 2004;282:115-30.

20. Lueßen HL, Lehr CM, Rentel CO, Noach ABJ, de Boer AG, Verhoef JC, et al. Bioadhesive polymers for the peroral delivery of peptide drugs. J Control Release. 1994;29:329-38.

21. Park H, Robinson JR. Physicochemical properties of water insoluble polymers important to mucin/epithelial adhesion. J Control Release. 1985;2:47-57.

22. Chun MK, Cho CS, Choi HK. Mucoadhesive microspheres prepared by interpolymer complexation and solvent diffusion method. Int J Pharm. 2005;20:288-95.

23. Chickering D, Jacob J, Mathiowitz E. Bioadhesive microspheres II. Characterization and evaluation of bioadhesion involving hard, bioerodible polymers and soft tissue. React Polym. 1995;25:198-206.

24. Sandri G, Poggi P, Bonferoni MC, Rossi S, Ferrari F, Caramella C. Histological evaluation of buccal penetration enhancement properties of chitosan and trimethyl chitosan. J Pharm Pharmacol. 2006;58:1327-36.

25. Bera K, Khanam J, Mohanraj KP, Mazumder B. Design and evaluation of mucoadhesive beads of glipizide as a controlled release drug delivery system. J Microencapsul. 2014;31(3):220-9.

26. Patel JK, Patel PP, Amin AF. Formulation and evaluation of mucoadhesive glipizide microspheres. AAPS Pharm Sci Technol. 2005;6(1):E49-55

27. Jamzad S, Fassihi R. Development of a controlled release low dose class II drug glipizide. Int J Pharm. 2006;312:24-32.

28. Belgamwar V, Shah V, Surana SJ. Formulation and evaluation of oral mucoadhesive multiparticulate system containing metoprolol tartarate: an in vitro-ex vivo characterization. Cur Drug Dev. 2009;6:113-21.

29. Palanisamy M, Khanam J, Arunkumar N, Rani C. Design and in vitro evaluation of poly ( $\varepsilon$-caprolactone) microspheres containing metoprolol succinate. Asian J Pharm Sci. 2009;4(2):121-31.

30. Chowdhury S, Majumdar S. Statistical optimization of fixed dose combination of glimepiride and atorvastatin calcium in immediate release tablet formulation. Int j Pharm Sci. 2010;2:194-200.

31. Yadav D, Survase S, Kumar N. Dual coating of swellable and rupturable polymers on glipizide-loaded MCC pellets for pulsatile delivery: formulation design and in vitro evaluation. Int $\mathrm{J}$ Pharm. 2011;419:121-30.

32. Madhusudhan S, Panda AK, Parimalakrishnan S, Manavalan R, Manna PK. Design, in vitro and in vivo evaluation of glipizide Eudragit microparticles. J Microencapsul. 2010;27(4):281-91.

33. Karasov WH, Diamond JM. A simple method for measuring intestinal solute uptake in vitro. J Comp Physiol B. 1983;152:105-11.

34. Bouer R, Barthe L, Philibert C, Tournaire C, Woodley J, Houin $\mathrm{G}$. The role of P-glycoprotein and intracellular metabolism in the intestinal absorption of methadone: in vitro studies using the rat everted intestinal sac. Fundam Clin Pharmacol. 1999;13:494-5.

35. Lee JW, Park JH, Robinson JR. Bioadhesive-based dosage forms: the next generation. J Pharm Sci. 2000;89:850-66.

36. Deasy PB, Collins AEM, Maccarthy DJ, Russell RJ. Use of strips containing tetracycline hydrochloride or metronidazole for the treatment of advanced periodontal disease. J Pharm Pharmacol. 1989;41:694-9.

37. Durig T, Fassihi R. Evaluation of floating and sticking extended release delivery systems: an unconventional dissolution test. J Control Release. 2000;67:37-44.

38. Nakanishi T, Kaiho F, Hayashi M. Use of sodium salt of carbopol 934P in oral peptide delivery. Int J Pharm. 1998;171:177-83. 
39. Ch'ng HS, Park H, Kelly P, Robinson JR. Bioadhesive polymers as platforms for oral controlled delivery II: synthesis and evaluation of some swelling, water-insoluble bioadhesive polymers. J Pharm Sci. 1985;74:399-405.

40. Verma RK, Garg S. Development and evaluation of osmotically controlled oral drug delivery system of Glipizide. Eur J Pharm Biopharm. 2004;57:513-25.

41. Florence AT, Attwood D. Physicochemical principles of pharmacy. 5th ed. London: Pharmaceutical Press; 2006. p. 492.

42. Behera BC, Sahoo SK, Dhal S, Barik BB, Gupta BK. Characterization of glipizide-loaded polymethacrylate microspheres prepared by an emulsion solvent evaporation method. Trop J Pharm Res. 2008;7(1):879-85.

43. Mahalaxmi R, Phanidhar S, Kumar S, Kalra A, Kanagale $\mathrm{PD}$, Narkhede R. Enhancement of dissolution of glipizide from controlled porosity osmotic pump using a wicking agent and a solubilizing agent. Int J Pharm Tech Res. 2009;1:70511.

44. Gaba P, Singh S, Gaba M, Gupta GD. Galactomannan gum coated mucoadhesive microspheres of glipizide for treatment of type 2 diabetes mellitus: in vitro and in vivo evaluation. Saudi Pharm J. 2011;19:143-52.

45. Kawaguchi H. Functional polymer microspheres. Prog Polym Sci. 2000;25:1171-210.
46. Phutane P, Shidhaye S, Lotlikar V, Ghule A, Sutar S, Kadam V. In vitro evaluation of novel sustained release microspheres of glipizide prepared by the emulsion solvent diffusion-evaporation method. J Young Pharm. 2010;2:35-41.

47. Putta S, Ashokkumar A, Anilkumar A. Formulation and in vitro evaluation of mucoadhesive microcapsules of glipizide with gum kondagogu. J Chem Pharm Res. 2010;2(5):356-64.

48. Chowdary KPR, Rao YS. Design and in vitro and in vivo evaluation of mucoadhesive microcapsules of glipizide for oral controlled release: a technical note. AAPS Pharm Sci Technol. 2003;4(3):1-6.

49. Maiti S, Ranjit S, Mondol R, Ray S, Sa B. $\mathrm{Al}^{+3}$ ion cross-linked and acetalated gellan hydrogel network beads for prolonged release of glipizide. Carbohydr Polym. 2011;85:164-72.

50. Ginski MJ, Polli JE. Prediction of dissolution-absorption relationships from a dissolution:Caco-2 system. Int J Pharm. 1999;177:117-25.

51. Kale JE, Kasliwal JE, Avari JE. Attempt to design continuous dissolution-absorption system using everted intestine segment for in vitro absorption studies of slow drug release formulations. Disso Technol. 2007;14:31-6.

52. Kahn CR, Shechter Y. Goodman and Gilman's the pharmacological basis of therapeutics, 8th ed. In: Theodore WR, Alan SN, Taylor P, Gilman AG editors. New York, NY: McGraw-Hill; 1991. p. 1712. 